\title{
REVELANDO MOTIVOS: ANÁLISE RETÓRICA DA CARTA-TESTAMENTO DE GETÚLIO VARGAS
}

\author{
UNVEILING THE REASONS: A RHETORICAL ANALYSIS OF THE LAST WILL AND \\ TESTAMENT LETTER OF GETÚLIO VARGAS
}

Evandro de Melo Catelão ${ }^{1}$

\begin{abstract}
RESUMO: Este estudo, parte integrante de doutorado em Letras, que tratou das formas e processos argumentativos presentes em textos produzidos por suicidas, busca resgatar parte desse foco apresentando a análise realizada da carta testamento de Getúlio Vargas. O texto em destaque foi a única ocorrência encontrada no Arquivo Público do Estado do Rio de Janeiro, organizados entre os outros documentos do gênero coletados em outras fontes. Sob um dos pontos de vista inseridos na análise, o retórico (foco deste artigo) contou com conceitos provenientes da Retórica e da Nova Retórica com vistas às escolhas dos argumentos e às projeções ethos, pathos e logos. Conclusões da pesquisa, nesse aspecto, mostraram que a carta-testamento apresentou um plano retórico ora centrado na acusação, ora no discurso epidíctico em exaltação ou louvor dos atos praticados, com a intenção de provocar um efeito de comunidade em função de um heroísmo. Nesse caso, o auditório era direcionado a unir-se em batalha contra uma força que se colocava sobre valores e direitos a serem defendidos, alterando a ligação do suicídio como falta de discernimento (ruina de si próprio) para uma bandeira de luta engajada, a entrega da vida por amor ou honra a um povo ou nação.
\end{abstract}

PALAVRAS-CHAVE: argumentação; produções de suicidas; Carta-testamento; retórica; discurso político.

\begin{abstract}
This study partially covers my doctoral research in Language, which dealt with the forms and processes present in argumentative texts produced by suicidal subjects. It aims to recover part of that focus by presenting the analysis of the last will and testament letter written by Getúlio Vargas. This text was the only one found in the Public Archives in Rio de Janeiro, organized among other documents of the kind collected from other sources. From one of the viewpoints within the analysis, the rhetorical one (the focus in this paper) relied on concepts from Rhetoric and New Rhetoric, aiming to know the chosen arguments and the projections ethos, pathos and logos. Research findings in this regard, showed that the letter/will rendered a rhetorical level centered either on the indictment, or on the epidictic speech in exaltation or praise of the committed acts with the intent to cause an effect of community in terms of heroism. In this case, the audience was directed to join a battle against the force that was placed on values and rights to be defended, and so, altering the relationship with suicide as a lack of discernment (ruining himself) for a flag engaged struggle, for the surrender of one's life for love or honor to his people or nation.
\end{abstract}

\footnotetext{
${ }^{1}$ Professor de Ensino Superior da Universidade Tecnológica Federal do Paraná - Câmpus Lonrina - UTFPRLondrina. Doutor em Letras pela Universidade Federal do Paraná - UFPR. E-mail: evandrocatelao@gmail.com
} 
KEYWORDS: argumentation; suicidal people written productions; last will and testament letter, rhetoric; political discourse.

Introdução

Inicialmente, a argumentação do suicida pode ser tomada como uma forma de composição elementar que pode ser expressa sob representações relativas a um esquema argumentativo, presente na memória discursiva dos sujeitos. Nos limites que se pretende traçar para a análise segundo o recorte retórico dessas produções, define-se o conceito do ato de argumentar como uma estratégia na qual são empregados inúmeros procedimentos. Essa estratégia é geralmente direcionada por uma ação assertiva/constativa a um coenunciador, envolvendo o compartilhamento de um ponto de vista. Enfatiza-se que a presente pesquisa insere-se nesse contexto, realizando um estudo de textos produzidos por suicidas sob uma perspectiva de análise textual/discursiva (ADAM, 2008) complementada por conceitos da Retórica e da Nova Retórica (PERELMAN \& TYTECA), esta última foco deste artigo.

Ressalta-se que a escolha e a motivação pelo estudo desses textos se basearam em análises exploratórias iniciais a partir de publicações de algumas dessas produções em periódicos de circulação nacional. Nessas análises observou-se que se tratava de um corpus que necessitava de uma atenção maior. A intenção de estudo voltou-se então para um campo de investigação textual e discursivo que conta com poucos trabalhos anteriores. Ao mesmo tempo, foram identificadas de antemão questões e lacunas ligadas ao tema, sobretudo em função do local de coleta das fontes, expressão do comportamento verbal escrito dos sujeitos, que fomentaram o desenvolvimento da pesquisa.

Após a delimitação e esclarecimento de algumas dessas lacunas, coletou-se o corpus, em sua maioria, em inquéritos policiais arquivados no Arquivo Nacional da cidade do Rio de Janeiro (ANRJ) e uma ocorrência no Arquivo Público do Estado do Rio de Janeiro (ocorrido no ano de 1954), objeto de análise deste trabalho.

As análises preliminares demonstraram que os conceitos selecionados da retórica propiciaram uma descrição discursiva bem mais evidente do que se fosse feita a opção apenas pelos aspectos textuais que primeiramente teriam sido alvo único da pesquisa. Verificou-se, também, que a estudo dos aspectos composicionais propiciação a visualização e elaboração de um quadro segundo o motivo para o suicídio ou para a escritura dos documentos. Nesses limites, foi possível traçar para as análises uma divisão entre os motivos apresentados para o suicídio, para a escritura dos documentos ou outro, revelando pontos de vista desses sujeitos em relação ao suicídio. 


\section{Suicídio e Discurso}

Não há dúvidas de que o suicídio provoca o imaginário das pessoas em muitos aspectos, estando em função do tempo e da sociedade aliado a inúmeros valores, crenças e fatos, que fazem com que seja considerado uma prática aceitável, uma conduta necessária em situações específicas, ou ainda um motivo de preocupação. Nesse último e mais representativo eixo, é visível o desconforto em relação ao suicídio, em função principalmente da prática de a morte voluntária afetar o organismo social, demonstrando certa fragilidade e incapacidade do homem visto que se desconhece boa parte de suas causas e motivações. Fruto de atividades ou ações sociais, o suicídio condensa um sentido de reprovação, principalmente nas culturas ocidentais, marcadas por dogmas cristãos em que a vida é tida como um dom divino e que somente pode ser tirada por uma força também divina. Pode-se admitir nessa apresentação geral uma série de pontos de vista que podem ser assumidos pelos sujeitos em função do valor que atribuem à vida humana, delimitados argumentativamente por proposições formadoras da visão que se tem do suicídio na sociedade atual.

Quanto a esses aspectos formadores dos pontos de vista dos sujeitos, Agrest (2010) apresenta aqueles relacionados à economia, ao avanço da ciência e à desmistificação da fé. Nessa disposição dos fatores, o sentido atribuído à vida sofre variação segundo a noção de produtividade admitida hoje e a que era admitida no passado. Aliado aos avanços tecnológicos, da ciência e da medicina, esse novo sentido tirou a visão natural da morte e esta passou a ser julgada com base na luta contra enfermidades crônicas e enfermidades terminais, as últimas consideradas "batalha perdida", fazendo com que a vida perdesse seu valor, ou que as pessoas perdessem a fé na vida, à medida que a morte era vista como inevitável. Seguindo o que afirma Agrest (2010), para o ato suicida, a minimização da morte se expressou em quatro práticas sociais: a) primeiramente pela incorporação do sentido de morrer como um ato sem grandes consequências. A morte se impõe assim como a vida e o sujeito pouco a pouco fica seguro sobre a decisão da morte voluntária; b) pela separação entre vida e morte - a morte que era sagrada, designada por Deus, passa a ser sinônimo de fracasso na sociedade da produção. Derrotada pela medicina, na sociedade do consumo, a morte é vista como penosa e antiestética para uma sociedade hedonista e ligada à imagem, à beleza, arrogantes frente à realidade da morte; c) relacionada ao tópico anterior, a dessacralização da morte ocorre pela mudança de valores em relação ao passado. Ao novo padrão de sociedade, menos voltado aos valores religiosos, a morte não é mais tida como vontade de Deus; d) por fim, acreditar que a 
morte não existe (negação da morte). Neste caso, há uma espécie de simplificação da morte e ampliação do sentido de matar/morrer como um ato merecido, em que matar ou se suicidar pela crença de se estar fora dos modelos sociais existentes é perfeitamente aceitável ou uma lei maior.

Como um padrão prévio do que se pode encontrar nos documentos, na cultura ocidental está profundamente arraigada uma marca religiosa cristã que liga o sentido de suicídio às práticas condenáveis em que a morte voluntária seria considerada uma espécie de "ruína a si próprio" e desencadearia uma série de sofrimentos e penalizações em uma outra vida (alma, espiritual). O cristianismo renega a prática suicida, a qual, ao ser propagada no ocidente, trouxe consigo a doutrina da santidade da vida humana, dádiva divina, bem dado por Deus e só tirado por ele. Dentro do dogma cristão, a escolha pela morte voluntária ocasiona tormentos eternos e condenação da alma com base em leis que regulam e castigam essa conduta. Em uma breve exemplificação dessa tradição de impedimento ao livre arbítrio da morte, no passado, pela lei eclesiástica da Idade Média, o suicida não poderia ser enterrado em solo sagrado, além disso, haveria confisco de seus bens e propriedades. Nos períodos posteriores à Idade Média, partes das leis provenientes das práticas cristãs foram transferidas e/ou ligadas a outras leis capitalistas. Era a ascensão do fator econômico em relação ao religioso anteriormente citado. No imaginário social essa mudança instituiu um regime de valores de autoexigência cobrada e transmitida aos familiares do suicida, com alguns exemplos representativos do lugar do suicida e de sua família na sociedade contemporânea da lógica mercadológica. Segundo essa autoexigência, o sujeito que deixa a vida por sua vontade escapa de suas obrigações, ou seja, comporta-se de forma irresponsável com sua nação. No Japão ocidentalizado, essa conduta era tão expressiva que era convencionado que um suicida transmitiria sua dívida de trabalho à família, devendo um ente próximo assumir sua função, fato ocasionado principalmente pela sucessão de suicídios na construção da ferrovia do Chuo Shinkansen, em que alguns pontos eram conhecidos como preferidos dos suicidas (STROM, sd. apud AGREST, 2010).

Como parte da conduta sócio-histórica dos sujeitos, esse histórico de valores e crenças gerou parte do que é admitido hoje e do que se acredita ser socialmente aceitável ou não em relação à morte voluntária. Diferentemente do local de ocorrência e dos princípios culturais formadores dos pontos de vista do suicídio para os sujeitos, a morte voluntária, grosso modo, constituiu-se um tabu e motivo de preconceito na sociedade contemporânea globalizada. Um ato, no consenso geral influenciado por dogmas religiosos, castigável, incompreendido, e que denota parte da incapacidade dos sujeitos frente à morte autoinfligida. No regime de leis, 
tradições eclesiásticas e provenientes das constituições socioeconômicas pós Idade Média passaram com o tempo à tradição legislativa do Estado, o que levou mais tarde a não conceituar o suicídio e a tentativa de suicídio como crime.

Esses dados foram compilados por Agrest (2010), segundo investigações de outros autores e estatísticas que revelaram dois campos distintos de crenças verdadeiras ou falsas em relação ao suicídio. Os registros discursivos de crenças dos sujeitos são divididos pela autora em crenças fundadas e crenças infundadas relativas às causas e motivações do suicídio, que neste trabalho serão retomados a partir dos fundamentos teóricos nas seções seguintes. As crenças fundadas se apoiam em princípios estatísticos apresentados em diferentes estudos de órgãos governamentais, sendo assim sustentadas como fatos ou verdades em que se assume uma pretensão de validade: a) O suicídio ocupa um dos primeiros postos entre as causas de morte; b) O suicídio é a manifestação de um transtorno mental; c) $\mathrm{O}$ álcool e as drogas contribuem para o risco de suicídio; d) Pessoas mais velhas se suicidam mais que as jovens; e) Metade das pessoas já pensou em suicídio;

f) Os homens se matam mais que as mulheres; g) O suicídio é um ato comum na comunidade gay; h) Os imigrantes se suicidam, as minorias étnicas não; i) O matrimônio ajuda a preservar a vida; j) O trabalho protege contra o suicídio;

1) Há famílias com uma clara tendência ao suicídio; m) O suicídio é contagioso.

Por outro lado, as crenças infundadas seriam as não validadas por estatísticas, mas que têm sua manutenção por meio de mitos e tabus que rodeiam o suicídio como uma prática socialmente estigmatizada, ligada sobretudo aos valores dos indivíduos. Apesar de não serem validadas, essas crenças também apresentam proposições que fundamentam a argumentação dos sujeitos: a) O suicídio é um hábito de algumas nações; b) $\mathrm{O}$ suicídio se encontra necessariamente unido ao amor juvenil (o mito de Romeu e Julieta); c) As pessoas geralmente se suicidam no inverno; d) As pessoas se suicidam à noite; e) Quem já tentou suicídio uma vez, não tentará novamente; f) As pessoas se matam com abuso de medicamentos.

\section{Limites da Análise Retórica}

A análise retórica utilizada na tese contou com a integração de conceitos da Retórica e Nova Retórica. No que se refere ao acordo e ao estabelecimento do discurso frente aos tipos de argumento, utiliza-se Perelman \& Olbrechts-Tyteca (1996) em diálogo com o que discute Reboul (2004) e alguns comentários de Breton (2003; 1999). Vale ressaltar que o que é 
discutido por Perelman \& Olbrechts-Tyteca (1996) e Reboul (2004) não foi primeiramente delineado com vistas ao tipo de análise proposto neste estudo, mas direcionado aos discursos jurídico e filosófico. Contudo, o "Tratado da Argumentação" (PERELMAN \& OLBRECHTS-TYTECA, 1996) é uma obra que se tornou clássica e uma síntese do pensamento aristotélico ao falar da argumentação sob fins analíticos, sendo uma referência no assunto e podendo ser adaptada a diferentes áreas de estudo da argumentação e à descrição de um corpus.

\subsection{Visão Retórica da Argumentação: $O$ Estabelecimento do Discurso e a Proposição dos Acordos}

Ao se incorporar a visão da argumentação segundo Breton (2003), foram incluídos para a visualização do corpus, três pontos considerados pelo autor como essenciais e que permitem definir o campo da argumentação partindo do que concebia a Retórica Clássica. No primeiro deles, considerar que argumentar equivale a comunicar, o que implica levar em conta orador, auditório e mensagem; em segundo lugar, observar que argumentar não é convencer a qualquer preço, o que implica romper com a retórica, pois ela não economiza meios para persuadir, tornando necessário buscar respaldo em teorias auxiliares, como a Nova Retórica; em último lugar, estar ciente de que "argumentar é raciocinar, propor uma opinião aos outros, dando-lhes boas razões para aderir a ela" (BRETON, 2003, p.26).

Pensando nesses limites, a teoria da argumentação nesses moldes volta-se aos participantes do discurso e a outros elementos (técnicas) do contexto de produção, assim como desenvolvem Perelman \& Olbrechts-Tyteca (1996). Discutindo a questão, Breton (2003) apresenta um esquema, que aqui foi adaptado relacionando os conceitos apresentados pelo autor com a categoria de acordo e técnicas de Perelman \& Olbrechts-Tyteca (1996), como abaixo (esquema 8). Nesse esquema, sistematiza-se uma situação argumentativa de produção, relacionando os elementos retóricos/discursivos a serem utilizados nas análises. Trata-se de uma maneira de visualização dos polos acionados no momento do estabelecimento do discurso e que, em linhas gerais, situa os objetos em discussão e auxilia na própria elaboração de um quadro argumentativo retórico das produções de suicidas (acordos, argumentos, ethos, pathos, ponto de vista, entre outros). No esquema, as atividades se concentram em torno do orador, seu auditório e os argumentos que direcionarão a tese principal (parte central do triângulo). O orador constrói uma imagem de si (ethos) e uma 
imagem do auditório (pathos), as quais propiciarão maior chance de adesão a sua opinião, transmitida a fim de "mobilizar as paixões" do auditório, seduzi-lo (realização do acordo), de forma que compartilhe da tese, por uma escolha sistematizada de argumentos (dados e proposições) com o objetivo de atender às intenções da produção do discurso, ou objetivo discursivo visado. No contexto de recepção criado, tem-se o modo de aprisionamento do auditório à tese, marcado pelos argumentos em função de um discurso objetivo, e/ou baseado na desinformação e/ou esteticismo.

Esquema 1: Limites da argumentação

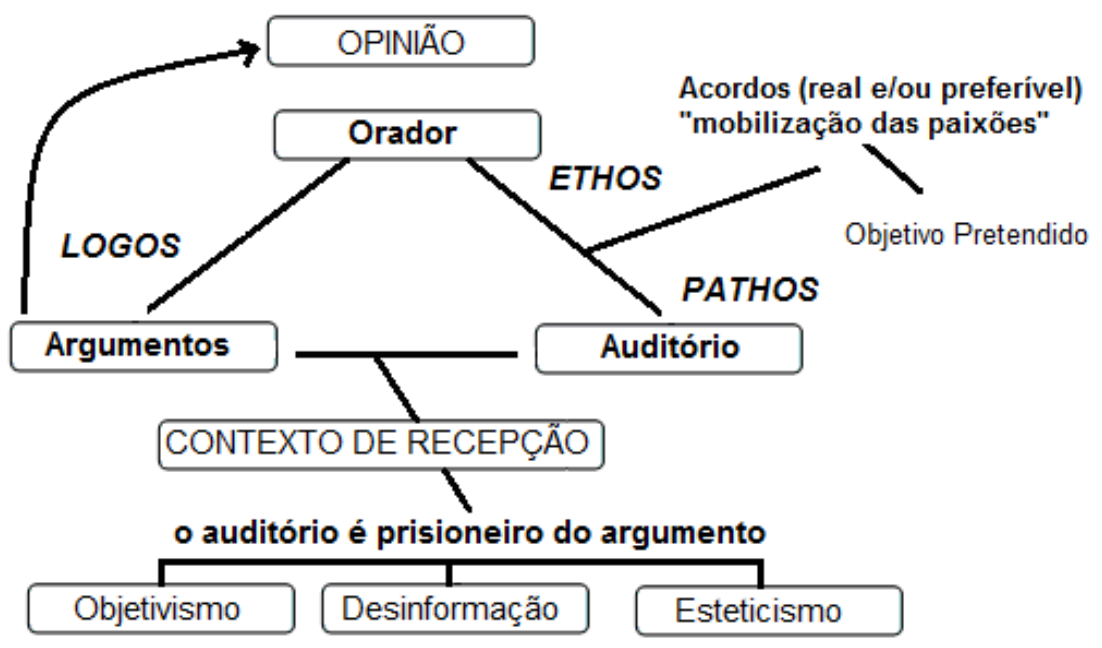

Esquema adaptado de Breton, 2003, p.53.

O esquema acima, adaptado do esquema de Breton (2003, p.53), apresenta a argumentação como uma atividade humana estritamente relacionada à ação de convencer ou compartilhar uma ideia, levando outrem à adoção da opinião pela escolha dos argumentos, estabelecimento de um acordo e das figuras de ethos e pathos criadas. Aponta para a possibilidade de aprisionamento pelo discurso, em que convencer pode também assumir uma perspectiva alternativa ao uso da força física como forma de adesão e sedução, por motivação implícita, sem que o coenunciador se dê conta, ou seja, por manipulação. A opinião, para Breton (2003), apresenta um sentido forte, pois seria representada por crenças que guiam as ações dos sujeitos, fazendo com que assumam determinadas condutas e organizem-se em grupos que compartilhem de uma mesma opinião. Em um paralelo com o que foi discutido no capítulo anterior, a opinião equivale ao ponto de vista $(\mathrm{PdV})$ dos sujeitos, ou responsabilidade enunciativa pelo enunciado. Na maioria das situações de produção, a adesão do auditório ao PdV do orador é o objetivo do discurso. 
O conceito de argumentação aparece primeiramente inserido na retórica e nela tem um ponto de partida nas discussões de como persuadir e principalmente dos tipos de argumentos como instrumentos de persuasão presentes no discurso (ethos e pathos - de ordem afetiva, e logos - de ordem racional). Seguindo esse princípio, Reboul (2004) afirma que uma das questões delimitadoras da argumentação está em "a quem" o discurso se destina e em sua consideração na interpretação do discurso, uma vez que esse é construído tendo em vista a imagem (pathos) que o orador/enunciador tem de seu auditório/coenunciador e as intenções do discurso. As bases dessa discussão são encontradas na Nova Retórica de Perelman, na qual o autor traça aspectos da argumentação na adesão ou não adesão do auditório a uma tese defendida por um orador, remetendo a vários conceitos.

Schmetz (2000), estudioso da obra do autor, aborda alguns desdobramentos que essa visão apresenta e que são importantes a considerar em razão do tipo de corpus da pesquisa. Por conta da noção de acordo, um aspecto central ficaria por conta do texto de Perelman ser dirigido a um tipo de discurso perfeito, ou que tem a pretensão de ser perfeito, que vislumbraria certas parcelas em detrimento de outras. Esse aspecto circunda as relações que todos os discursos deveriam ter em função de seus objetivos discursivos visados. Aproveita-se essa observação para a pesquisa (o que levaria a uma possibilidade de utilização dos conceitos do autor para além de sua obra), minimizando-a e tomando como ponto-chave a noção de que, ao construir seu discurso, todo orador tem por objetivo a perfeição, ou que, pelo menos, a compreensão e o julgamento desse discurso pelo auditório sejam adequados. Para tanto, retoma-se novamente o esquema 1 . Tanto do ponto de vista do discurso quanto da retórica, o ato de argumentar exige a consideração do outro, do contexto de recepção estabelecido pela seleção de acordos entre o orador e seu auditório, este último aprisionado aos argumentos do orador. Trata-se, portanto, de dar atenção às proposições prévias presentes na argumentação, sem as quais não seria possível estabelecer o discurso.

\subsection{Os Tipos de Argumentos como Mecanismos da Argumentação}

Cada escolha realizada em detrimento de outras na seleção e apresentação dos dados ou premissas que servirão à tese pode direcionar mais ou menos o auditório. Para a pesquisa, essas escolhas representam uma forma de exibição de particularidades dos documentos produzidos por suicidas, uma espécie de caracterização que só poderia ser visualizada com base no exame de uma espécie de teia argumentativa composta pelos tipos de argumentos 
eleitos para fazer parte do discurso. Uma distinção dos tipos de argumentos foi realizada por Perelman \& Olbrechts-Tyteca (1996) com a denominação de técnicas argumentativas. Tratase, como afirmam os próprios autores, da análise da estrutura de elementos que compõem a argumentação isoladamente, mesmo que se reconheça que sua significação só se constrói quando em relação ao seu todo. Em outras palavras, é preciso considerar em qualquer análise que todo discurso é determinado por sua situação de produção, sendo assim, sua significação/resultado final não pode ser medido senão em uma articulação entre todas as partes que o compõem, com o objetivo de não perder elementos de ligação e que podem permear um tipo de argumento selecionado e outro.

Os tipos de argumentos observados pelos autores inserem-se em dois grandes eixos esquemáticos argumentativos, que são, em sua essência, complementares e operantes em conjunto. Desse modo, um funciona conforme processos de ligação (aproximação de argumentos com o objetivo de estruturá-los e impor valor positivo ou negativo) e outro segundo processos de dissociação e ruptura (reparação de argumentos considerados solitários, modificando sistemas de noção). As técnicas de ligação são organizadas em i) argumentos quase-lógicos; ii) argumentos baseados na estrutura do real; iii) argumentos que visam fundamentar a estrutura do real. O grupo de argumentos baseados na estrutura do real apresenta as técnicas de ruptura de ligação e dissociação caracterizadas todas em um único subeixo esquemático pelos autores. Cada subcategoria de técnicas apresenta uma série de subramificações internas e traços argumentativos intermediários entre uma classe de argumentos e outra. Um conjunto simplificado e geral das técnicas pode ser visualizado abaixo (esquema 9). Ao se elaborar o esquema não se pretendia ser exaustivo na demonstração de todos os tipos de argumentos apresentados pelos autores, sendo apenas uma forma de visualização geral das técnicas.

Esquema 2: Técnicas argumentativas 


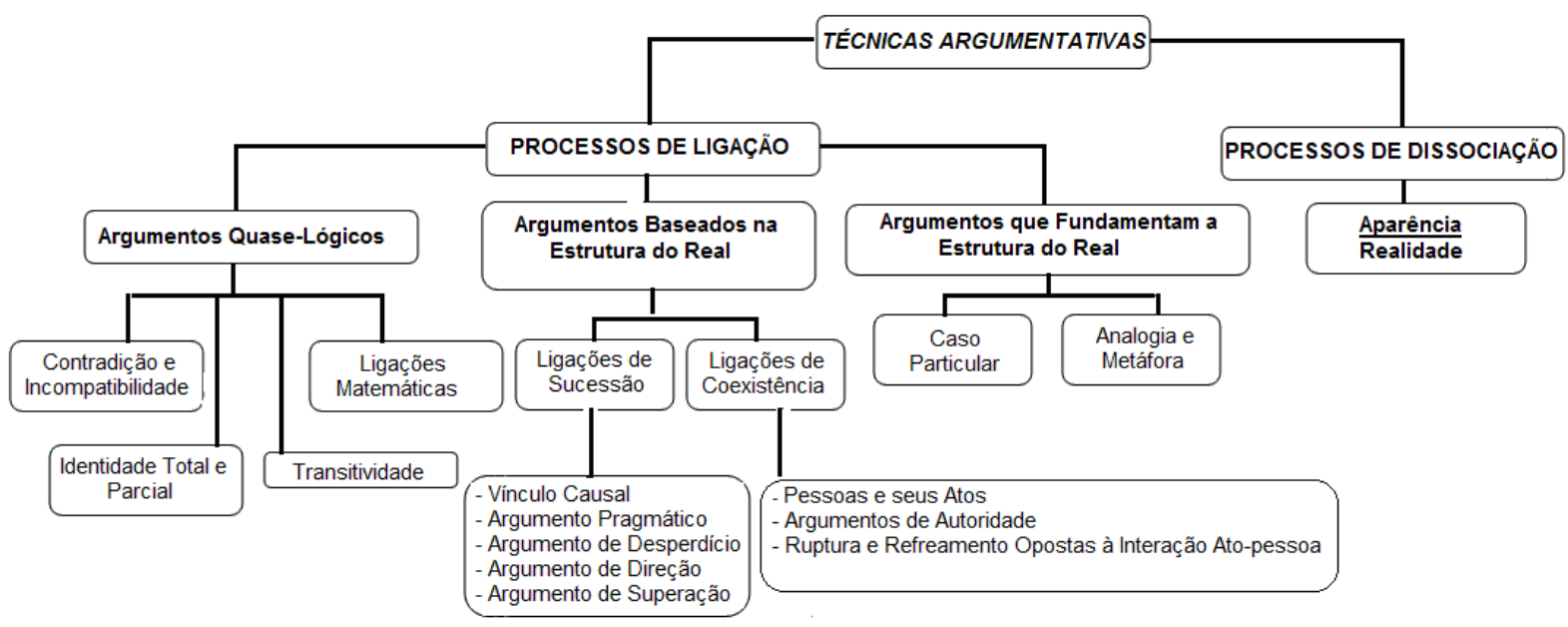

O esquema possibilita uma observação globalizada das principais técnicas e dos limites e sub-relações entre si, atendo-se ao fato de que, segundo os próprios autores e, como já se destacou anteriormente, o esquema de técnicas é proveniente da interpretação e divisão em classes das palavras do orador, podendo, nesse caso, apresentar falhas, ou não ser de todo claro. Trata-se de quatro formas ou esquemas argumentativos sob os quais se reduzem os objetos de acordo nos discursos, um referencial que, apesar de não ter sido elaborado em atenção ao tipo de discurso em foco, permite sua descrição, bem como identificação de elementos coocorrentes entre os documentos. As relações expressas no esquema 9 possibilitam a descrição dos movimentos argumentativos no que seria um quadro de representações possíveis entre o orador e o auditório, nas palavras de Perelman \& OlbrechtsTyteca (1996), dados da argumentação entre o orador e o auditório que permitem modificar um estado de coisas preexistente, reforçar valores, entre outras ações.

Em atenção ao corpus escolhido para a análise destaca-se, para explicitação e utilização no estudo, apenas parte das técnicas citadas no esquema 2, esta escolhida entre as que se acreditou corroborarem com as características principais dos documentos produzidos por suicidas. Nesse sentido, faz-se a descrição de uma parcela das técnicas relativas aos processos de ligação, a classe de argumentos baseados na estrutura do real e os argumentos que fundamentam a estrutura do real, principalmente porque a estrutura argumentativa dos documentos é marcada por proposições factuais. Entre os argumentos quase-lógicos, uma última observação em relação às técnicas ficará por conta dos princípios de contradição e incompatibilidade.

\section{Análise: Política e o Suicídio como um Ato Heroico}


Desde o momento em que foi encontrada, a Carta Testamento de Getúlio Vargas gerou inúmeras interpretações e análises em torno de sua produção. A sua reprodução aqui não pretende exaurir todas as questões que o documento suscita - uma vez que se reconhece que isso demandaria um trabalho específico para esta tarefa -, assim como já foi apontado anteriormente por outros autores em análises dos discursos de Vargas (OSAKABE, 1979). Contudo, ao se falar em documentos produzidos por suicidas, não se poderia deixá-la de lado. Assim, propôs-se sua inclusão segundo os objetivos da presente pesquisa, salientando-se, à medida que se reconhece outros estudos (nas áreas de Sociologia e de Política), que se trata apenas do exame da argumentação do suicida segundo os fundamentos adotados para esse tipo de composição.

Conforme dados da página da Fundação Getúlio Vargas (FGV, 2012), o documento foi encontrado ao lado do corpo de Vargas, com sua assinatura e dirigido ao povo brasileiro. Na carta, segundo a instituição, são explicitadas as razões que levaram o então presidente ao suicídio. Nela, são indicados como responsáveis "grupos internacionais cujos interesses o governo contrariara, aliados a grupos nacionais que se opunham ao que Vargas definia como 'o regime de garantia do trabalho", esse fato acabaria com os direitos assegurados pelo governo brasileiro (FGV, 2012, s.p.). No documento, é clara a postura de Vargas como defensor e libertador do povo e sua morte como uma forma de prova dessa entrega.

Ainda de acordo com a página da FVG, existem dúvidas quanto à real autoria do documento, chegando sua redação a ser atribuída ao jornalista José Soares Maciel Filho, que também redigia boa parte dos discursos do presidente Vargas. Na mesma página eletrônica, há a informação de que no Centro de Pesquisa e Documentação de História Contemporânea do Brasil (CPDOC) estão arquivadas duas cópias, uma datilografada (texto transmitido do Palácio do Catete à Rádio Nacional, por telefone, horas depois da confirmação do suicídio), sendo um texto mais conciso com conteúdo proposicional semelhante.

T4 foi o único documento encontrado no Arquivo Público do Estado do Rio de Janeiro (Arquivo Público do Estado do Rio de Janeiro, Fundo Polícias Políticas do Rio de Janeiro, setor DGIE, notação 278, folhas 125) e caracteriza-se como uma reprodução da carta testamento de Getúlio Vargas, sem data, em panfleto com duas páginas, sendo na frente a carta e no verso a apresentação dos objetos requeridos com o título "A luta principal dos trabalhistas". Por motivos de autorização de divulgação da íntegra do documento, utiliza-se a cópia cedida pelo arquivo. Para a análise, leva-se em conta, entretanto, o contexto de produção de 1954 segundo dados disponibilizados pela Fundação Getúlio Vargas (FGV, 2012), anteriormente apresentados. 


\section{Detalhe do original}

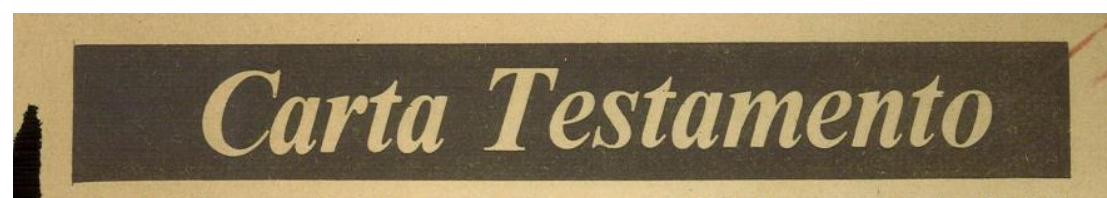

(Deixada no dia de sua morte, em 24 de agosto de 1954)

Mais uma vez, as forças e os interesses Getulio Vargas contra o povo coordenaram-se e novamente se desencadeiam sobre mim.

Não me acusam, insultam; não me combatem, caluniam e não me dão o direito de defesa. Precisam sufocar a minha voz e impedir a minha ação, para que eu não continue a defender, como sempre defendi, o povo e principalmente os humildes. Sigo o destino que me é imposto. Depois de decênios de dominio e espoliação dos grupos económicos e financeiros internacionais, fiz-me chefe de uma revolução e venci. Iniciei o trabalho de libertação e instaurei o regime de liberdade social. Tive de renunciar. Voltei ao governo nos braços do povo. A campanha subterrânea dos grupos internacionais aliou-se à dos grupos nacionais revoltados contra o regime de garantia do trabalho. A lei de lucros extraordinários foi detida no Congresso. Contra a justiça da revisão do salário mínimo se desencadearam os ódios. Quis criar a liberdade nacional na potencialização das nossas riquezas através da Petrobrás e, mal começa esta a funcionar, a onda de agitação se avoluma. A Eletrobrás foi obstaculada até o desespero. Não querem que o trabalhador seja livre. Não querem que o povo seja independente.

Assumi o governo dentro da espiral inflacionária que destruia os valores de trabalho. Os lucros das empresas estrangeiras alcançavam até $500 \%$ ao ano. Nas declaraçōes de valores do que importávamos existiam fraudes constatadas de mais de 100 milhōes de dólares por ano. Veio a crise do café, valorizou-se o nosso principal produto. Tentamos defender seu preço e a resposta foi uma violenta pressão sobre a nossa economia, a ponto de sermos obrigados a ceder.

Tenho lutado mês a mês, dia-a-dia, hora a hora, resistindo a uma pressão constante, incessante, tudo suportando em silêncio, tudo esquecendo, renunciando a mim mesmo, para defender o povo, que agora se queda desamparado. Nada mais vos posso dar, a não ser meu sangue. Se as aves de rapina querem o sangue de alguém, querem continuar sugando o povo brasileiro, eu ofereço em holocausto a minha vida. Es-

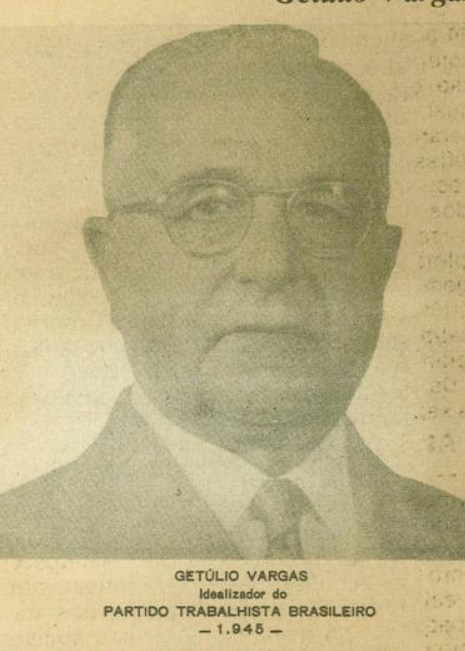

colho este meio de estar sempre convosco. Quando vos humilharem, sentireis minha alma sofrendo ao vosso lado. Quando a fome bater à vossa porta, sentireis em vosso peito a energia para a luta por vós e vossos filhos. Quando vos vilipendiarem, sentireis no pensamento a força para a reação. Meu sacrificio vos manterá unidos e meu nome será a vossa bandeira de luta. Cada gota de meu sangue será uma chama imortal na vossa consciéncia e manterá a vibração sagrada para a resistência. Ao ódio respondo com perdão. E aos que pensam que me derrotaram respondo com a minha vitória. Era escravo do povo e hoje me liberto para a vida eterna. Mas esse povo de quem fui escravo não mais será escravo de ninguém. Meu sacrificio ficará para sempre em sua alma e meu sangue será o preço do seu resgate.

Lutei contra a espoliação do Brasil. Lutei contra a espoliação do povo. Tenho lutado de peito aberto. O ódio, as infámias, a calúnia não abateram meu ânimo. Eu vos dei a minha vida. Agora vos ofereço a minha morte Não receio. Serenamente dou primeiro passo no caminho da eternidade $e$ saio da vida para entrar na História. 
a) Plano de texto e sequencialidade

De base argumentativa, o plano de texto da Carta apresenta-se de forma complexa, situando-se próximo ao que seria um plano de texto ocasional. O documento em si apresenta uma estrutura que varia entre a carta pessoal, o pronunciamento (declaração pública) e, como efeito da argumentação, o testamento. O documento em questão é, portanto, uma produção singular, uma vez que o plano de texto fixo, segundo Adam (2008), surge progressivamente, visto que vai se tornando estruturalmente significativo, ou seja, por sua recorrência.

Verifica-se que a "carta testamento" apresenta-se estruturalmente organizada pelo plano retórico clássico - disposição - (exórdio, narração/confirmação, peroração) em função do que poderia ser considerado primeiramente um pronunciamento ao povo. Contudo, como já se abordou no tópico anterior sobre esquematização discursiva, a situação sociodiscursiva de produção remete às intenções do autor, sujeito empírico, de deixar por escrito as intenções/motivações que antecederam o suicídio e, nesse sentido, o documento teria características da carta (carta de suicídio), apesar de não exibir marcas do gênero, como a seção de abertura e fechamento. Na mesma direção, o texto assumiu também a perspectiva de testamento, principalmente em função do legado deixado a partir do suicídio, que representaria metaforicamente uma herança/legado ao povo. Nesse último direcionamento, essa interpretação do discurso (que remete a Vargas) como testamento é gerada mais por um efeito do discurso junto ao contexto de recepção do que por sua estrutura.

\section{Carta testamento}

(deixada no dia de sua morte, em 24 de agosto de 1954)

Getúlio Vargas - Idealizador do Partido Trabalhista Brasileiro em 1945.

<EXÓRDIO> [1]Mais uma vez, as forças e os interesses contra o povo coordenaram-se novamente e se desencadeiam sobre mim.

<CORPO DA ARGUMENTAÇÃO/NARRAÇÃO>[2]Não me acusam, me insultam; não me combatem, caluniam e não me dão o direito de defesa. [5]Precisam sufocar a minha voz e impedir a minha ação, para que eu não continue a defender como sempre defendi, o povo e principalmente os humildes. [6]Sigo o destino que me é imposto. [7]Depois de decênios de domínio e espoliação dos grupos econômicos e financeiros internacionais, fiz-me chefe de uma revolução e venci. [8]Iniciei o trabalho de libertação e instaurei o regime de liberdade social. [9]Tive que renunciar. [10]Voltei ao governo nos braços do povo. [11]A campanha subterrânea dos grupos internacionais aliou-se à dos grupos nacionais revoltados contra o regime de garantia do trabalho. [12]A lei de lucros extraordinários foi detida no Congresso. [13]Contra a Justiça da revisão do salário-mínimo se desencadearam os ódios. [14]Quis criar a liberdade nacional na potencialização das nossas riquezas através da Petrobrás, mal começa esta a funcionar, a onda de agitação se avoluma. [15]A Eletrobrás foi obstaculada até o desespero. [16]Não querem que o trabalhador seja livre. [17]Não querem que o povo seja independente.

[18]Assumi o Governo dentro da espiral inflacionária que destruía os valores do trabalho. [19]Os lucros das empresas estrangeiras alcançavam até $500 \%$ ao ano. [20]Nas declarações de valores do que importávamos 
existiam fraudes constatadas de mais de 100 milhões de dólares por ano. [21]Veio a crise do café, valorizou-se o nosso principal produto. [22]Tentamos defender seu preço e a resposta foi uma violenta pressão sobre a nossa economia a ponto de sermos obrigados a ceder.

<CONFIRMAÇÃO>[23]Tenho lutado mês a mês, dia a dia, hora a hora, resistindo a uma pressão constante, incessante, tudo suportando em silêncio, tudo esquecendo, renunciando a mim mesmo, para defender o povo que agora se queda desamparado. [24]Nada mais vos posso dar a não ser meu sangue. [25]Se as aves de rapina querem o sangue de alguém, querem continuar sugando o povo brasileiro, eu ofereço em holocausto a minha vida. [26]Escolho este meio de estar sempre convosco. [27]Quando vos humilharem sentireis minha alma sofrendo ao vosso lado. [28]Quando a fome bater à vossa porta, sentireis em vosso peito a energia para a luta por vós e vossos filhos. [29]Quando vos vilipendiarem, sentireis no meu pensamento a força para a reação. [30]Meu sacrifício nos manterá unidos e meu nome será a vossa bandeira de luta. [31]Cada gota de meu sangue será uma chama imortal na vossa consciência e manterá a vibração sagrada para a resistência. [32]Ao ódio respondo com o perdão. [33]E aos que pensam que me derrotaram respondo com a minha vitória. [34]Era escravo do povo e hoje me liberto para a vida eterna. [35]Mas esse povo de quem fui escravo não mais será escravo de ninguém. [36]Meu sacrifício ficará para sempre em sua alma e meu sangue terá o preço do seu resgate.

<PERORAÇÃO>[37]Lutei contra a espoliação do Brasil. [38]Lutei contra a espoliação do povo. [39]Tenho lutado de peito aberto. [40]O ódio, as infâmias, a calúnia, não abateram meu ânimo. [41]Eu vos dei a minha vida. [42] Agora ofereço a minha morte. [43]Nada receio. [44]Serenamente dou o primeiro passo no caminho da eternidade e saio da vida para entrar na história.

Ainda que não bem marcado, em [1] tem-se o exórdio, o qual, assim como nos manuais de retórica, tem a função de tornar o auditório "dócil, atento e benevolente" (REBOUL, 2004, p.55), ou seja, propenso a apreender a informação e também chamar a atenção sobre o ethos, direcionando o interesse em defesa do povo (mobilização dos afetos) e à suposição de perseguição. A partir de [2], a ênfase é claramente no logos e aí se situam os fatos - por meio de uma narração com a expressão de continuidade/sequência das ações, ou raciocínio por continuidade dos fatos - que farão parte das teses de "suicídio, portanto liberdade do povo", "suicídio, portanto legado ao povo". Em [23], apresentam-se os dados que seriam a "confirmação" dos fatos, com o conjunto de atitudes frente aos dados e às novas teses: (“[24]Nada mais vos posso dar a não ser meu sangue. [25]Se as aves de rapina querem o sangue de alguém, querem continuar sugando o povo brasileiro, eu ofereço em holocausto a minha vida"; "[30]Meu sacrifício nos manterá unidos e meu nome será a vossa bandeira de luta". A liberdade do povo é proveniente de um movimento argumentativo de fluxo de informação, ou transitividade de um dado a outro em "[34]Era escravo do povo e hoje me liberto para a vida eterna. [35]Mas esse povo de quem fui escravo não mais será escravo de ninguém". Verifica-se que o sentido de escravidão apresenta dois direcionamentos, a escravidão do povo (como algo a ser combatido) e a escravidão do orador ao povo (oferecida). Por fim, na peroração, ou término do discurso, ocorre o momento mais importante no sentido de mobilização dos afetos no contexto de recepção dos dados. São empregadas nesse momento três estratégias com o objetivo primeiro de recapitular, "[38]Lutei contra a espoliação do Brasil. [38]Lutei contra a espoliação do povo. [39]Tenho lutado de peito aberto. [40]O ódio, as infâmias, a calúnia, não abateram meu ânimo", e, em 
contrapartida, de amplificar o poder da tese e por fim propor adesão pela sedução (mobilização das paixões) que recai profundamente sobre o pathos: "[41]Eu vos dei a minha vida. [42]Agora ofereço a minha morte. [43]Nada receio. [44]Serenamente dou o primeiro passo no caminho da eternidade e saio da vida para entrar na história”.

b) O suicídio como um ato heroico no quadro retórico

Lembrando das questões relativas aos gêneros retóricos clássicos, o discurso em questão assemelha-se, principalmente pelo auditório entendido, ao gênero epidíctico em função do louvor dos atos em razão da busca de adesão desse auditório à tese. Segundo Adam (2010, p.125), "a força do epidíctico está precisamente em criar retoricamente uma indivisão, um efeito de comunidade, de postular essa homonö̈a como um fato e exaltá-la", o que claramente é o foco da Carta Testamento, propor valor de comunidade e, de forma especial, de exaltação do heroísmo, da entrega em "holocausto" pelo povo, pelos humildes. Para tanto, o recurso utilizado para o louvor é a repetição, sobretudo de lexemas, como forma de amplificação da tese, de aproximação e de incitar a resistência contra os que lutam contra a liberdade do trabalho ("> [23]Tenho lutado mês a mês, dia a dia, hora a hora"; " $>[37]$ Lutei contra a espoliação do Brasil. [38]Lutei contra a espoliação do povo. [39]Tenho lutado de peito aberto"). Há também uma repetição qualitativa por adjetivos como "lucros extraordinários", "chama imortal".

Quantos aos acordos, a ancoragem em fatos (acordo com o real) busca incessantemente fazer sentido, ser crível e tem a pretensão de validar a tese presente na passagem marcada em [30], [31], [36] “o sacrifício da vida em nome do povo”. Em [18], [19] e [20] tem-se uma amostra dessa ancoragem em fatos. Trata-se de um recurso para legitimar o documento como um testamento e o suicídio como um ato de heroísmo, legado deixado ao povo. O suicídio, nesse caso, é um ato de heroísmo em que o indivíduo busca consolidar sua imagem, fazer parte da lembrança por seu ato "heroico", perpetuar a essência de seu ato. Esse sentido é apresentado por Agrest (2010) no momento em que cita o valor do suicídio para algumas culturas como podendo ser um ato nobre e digno de ser lembrado. Observa-se que o discurso, ao recorrer aos fatos, busca um acordo com o auditório universal, expondo suas atitudes e marcando sua autoridade, assim contribuindo ainda mais para que o texto seja verossímil. Um esquema retórico poderia ser traçado no seguinte sentido: 


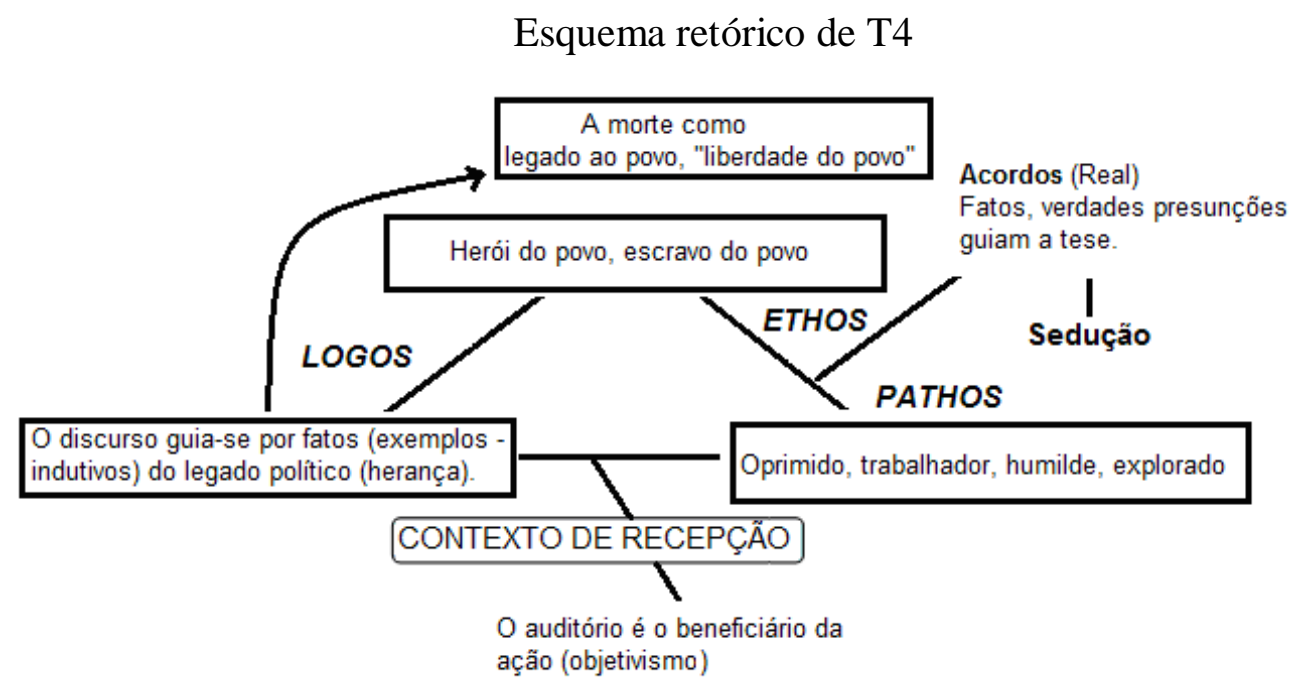

Para os objetivos da pesquisa de descrição dos documentos produzidos por suicidas, o que chama mais atenção no esquema retórico de T4 é o fato de o discurso se direcionar à exploração da imagem da morte como uma forma de legado ao povo, ou seja, às parcelas mais humildes da sociedade brasileira. Nos dois polos da afetividade, o ethos volta-se à criação de uma imagem de "herói do povo", ao mesmo tempo em que no pathos (mobilização das paixões) caminha no sentido de suscitar o sentimento de opressão e de escravidão em um povo descrito como humilde e desamparado. Nesse sentido, no contexto de recepção, o povo, destinatário do discurso, seria o beneficiário das consequências ocasionadas pelo suicídio. $\mathrm{O}$ suicídio torna-se um símbolo de morte heroica, consagrando pelo discurso um tipo de ethos próprio do cenário dos homens públicos, inseridos na política a ponto de formar um estereótipo, um personagem-tipo. A criação dessa imagem é definitivamente originada no logos pelo que a retórica denomina phronesis (objetivo, sensato, ponderado), na escolha dos fatos que descrevem uma trajetória de luta e total entrega em favor do povo, próprio das epopeias literárias. Nessa "jornada de herói”, têm-se propriamente todos os passos seguidos no discurso, apresentação dos inimigos, das provações e finalmente a recompensa, que seria destinada ao povo. Esse herói ressurge, assim como na literatura, e imortaliza-se 
(“[44]Serenamente dou o primeiro passo no caminho da eternidade e saio da vida para entrar na história"), ao mesmo tempo que deixa sua herança, tornando-se símbolo de luta a ser apropriado.

c) Técnicas argumentativas no discurso heroico

Entre as técnicas argumentativas, um tipo de argumento que chama atenção no texto é o emprego de técnicas que fundamentam a estrutura do real, como metáforas e analogias. Nessa argumentação, a metáfora, por exemplo, tem o poder de trazer à palavra uma mudança de sentido bem sucedida, na medida em que é redutora e, por isso, capaz de tornar a tese principal defendida mais aceitável. Observa-se esse emprego em [25] na apropriação do sentido de "aves de rapina" para a exploração de outras vidas em "Se as aves de rapina querem o sangue de alguém, querem continuar sugando o povo brasileiro, eu ofereço em holocausto a minha vida". Nesse exemplo, a metáfora condensa uma analogia e expressa elementos do tema e do foro, traduzindo semelhança em identidade. Em outras palavras, aves de rapina corresponderiam aos grupos nacionais e internacionais contra o povo e o ato de sugar o sangue ou exploração da vida alheia estaria relacionado à exploração do trabalho do povo, o que em uma condensação analógica resultaria em:

\section{Tema}

A aves de rapina

B grupos internacionais e nacionais
Foro

C sugar o sangue

D sugar o sangue do povo
Relação

exploração de vidas

exploração do povo

Em [44], tem-se um caso de analogia, agora em relação ao sentido de suicídio empregado em "Serenamente dou o primeiro passo no caminho da eternidade e saio da vida para entrar para a história". Essa analogia consiste na transposição de uma estrutura de uma área de conhecimento a outra a ela similar, no caso entre a morte (foro ou elemento mais conhecido da proposição) como forma de eternização na história (o termo menos conhecido em que será realizada a relação). Em [44], não se tem um caso de composição de quatro termos (A está para B assim como C está para D), mas uma composição com três elementos, com repetição de um dos termos, no caso A está para B, assim como C está para B. Por essa fórmula, o "suicídio estaria para eternidade assim como entrar para a história estaria para o suicídio", em que dar o primeiro passo para eternidade (suicídio) e sair da vida (suicídio) 
estariam em campos diferentes, podendo essa relação ser vista também como uma analogia de quatro termos. Trata-se de um valor indutivo dentro da proposição argumentativa defendida que não pode ser negado como um prolongamento do sentido de morrer, sendo por si persuasivo ao auditório a que se destina.

Outra técnica que merece destaque no texto é a ligação da pessoa e seus atos. Ela aparece arraigada precisamente à construção da imagem de si no texto. Trata-se da identificação da pessoa projetada no interior do discurso por seus atos segundo apresentados junto às premissas que compõem a proposição argumentativa. Como discutido entre os fundamentos, a identificação da pessoa por seus atos ocorre junto ao que se chama de uma previsão de pessoas-tipo, ou personagens-tipo, proveniente da análise de seus atos os caracterizando, por exemplo, como conservadores, sensatos, solidários e até como um herói, como é o caso de T4. Observa-se que em T4 a imagem do autor discursivo suicida ganha uma acepção própria que, apesar de a cultura em que está inserido não comportar essa présignificação do suicídio, a análise dos atos que são apresentados em função da entrega em sacrifício próprio e do suicídio como forma de libertação de outros funciona como uma regra já admitida "do sacrifício de um para o bem de todos". Nesses limites, o suicídio sai dos limites do sujeito que caiu em desgraça para um sujeito que passa a ser considerado um indivíduo honrado, salvador, redentor.

A imagem de herói exprime em T4 a autoridade necessária para que o discurso seja admitido pelo auditório, estando presente entre as premissas que ligam esse discurso ao bem do povo, ao bem dos humildes. Como apresentado anteriormente, a confiança no discurso, situada na imagem de ethos, é proveniente da sabedoria, ou seja, da phronesis. O ethos em T4 é criado no logos, no interior das premissas que compõem a proposição argumentativa. Não se pode negar que o discurso de Vargas torna-se crível justamente pela virtude expressa no interior dos dados apresentados e direcionadores da tese de suicídio como legado e libertação/salvação dos mais humildes.

\section{Conclusões}

Na discussão a partir do referencial retórico, toma-se como ponto inicial a premissa de que todo discurso tem em vista a perfeição ou que o auditório o julgue como adequado. Dito de outra forma, o ato de argumentar exige a consideração do outro, ou seja, de um acordo a ser estabelecido com um auditório real ou potencial. $\mathrm{O}$ acordo como técnica exige que o orador pré-visualize e pense seu discurso visando a provocar a adesão desse auditório à tese 
defendida. No que corresponde à produção do suicida, esse acordo esteve ligado ora a um auditório universal, ora em função de valores, a sujeitos particulares. A utilização de acordos nos dois níveis (do real e do preferível) foi uma estratégia selecionada claramente em função do tipo de motivação que estaria expressa junto aos enunciados. Os discursos partiram, principalmente quando há uma reconceituação do suicídio, como aparece na carta/testamento de Vargas (T4), de acordos com o real, utilização de fatos e verdades com a função principal de atingir um auditório potencial conservador e que, sobretudo, recusa ou destitui a tese de suicídio como prática aceitável.

Por outro lado, no intuito de reforçar um ethos idôneo, os documentos por motivação amorosa, problemas familiares e financeiros, política e alguns casos sem motivação explícita articularam-se também em direção aos valores, hierarquias e lugares do preferível (acordo com o preferível), com função clara de demonstrar ciência do ato e mobilização dos afetos. Entre as análises, observa-se uma intensa articulação entre a conduta suicida e a demonstração de ciência dos atos, ora por fatos, ora por valores, uma maneira corrente de propor sua argumentação e tentar provocar adesão às teses defendidas. Essas teses se mostraram quase sempre emblemáticas de uma voz social de que "nada justificaria o suicídio", tanto religiosa (condenação) quanto economicamente (o homem que foge de seus compromissos e deixa uma dívida social).

Todos esses aspectos fazem com que seja também necessário outro direcionamento no sentido da imagem de auditório apresentada. Nesses imites, visualiza-se uma apresentação dos acordos e entendimento entre esse orador e seu auditório (classificação utilizada por SCHMETZ, 2000), em uma divisão dos tipos de argumentos entre os que buscam convencer dos que visariam, sobretudo, a persuadir. Há nessa classificação um distanciamento entre convencer e persuadir, em que persuadir teria uma força maior tendo em vista a chance de adesão à tese mais provável ou não. Essa tarefa traria em si uma divisão entre argumentos de razão e argumentos sofísticos (falsos). Uma representação dos dados nessas duas direções ficaria pelos discursos de reconceituação do suicídio, que em T4 ficou centrado na libertação do povo. Nesses textos de reconceituação, os argumentos visam a mais que convencer/afirmar, persuadir o interlocutor à adesão à tese e que minimizar a rejeição do suicídio como uma conduta imprópria. Ao auditório também seria atribuído um encargo, ou responsabilidade pelo julgamento dos argumentos nessas duas classes, criando um estado de espírito no auditório para a adoção do discurso com base em um ideal compartilhado, um procedimento moral aceitável, a defesa de um incapacitado, exemplos de comportamento. 
A argumentação por acordo com o real (fatos, verdades e presunções) foi recorrente. Em T4, os atos em benefício do povo direcionam a manutenção da honra. No tocante à argumentação e à própria hipótese central do trabalho, esse caráter entre as composições é mais um dado que se soma a uma conduta compartilhada, ou seja, partir da crença da exclusão à premissa desejada, seja mostrando-se preso a uma moral burguesa ou ao amor idealizado, seja pela demonstração de dever ou graça merecida. Esse fato é comprovado pelo próprio teor das motivações para o suicídio ou escritura que permitiram a classificação dos documentos entre causas amorosas, financeiras, políticas, de conduta moral/religiosa e familiar.

Retórica e argumentativamente, a forma epistolar, com suas constantes composicionais, foi o modo encontrado pelo suicida para traçar sua argumentação. A apresentação da divisão segundo as regras da arte retórica (disposição) mostrou-se pertinente, a contar pelo tipo de gênero utilizado (cartas e bilhetes). Apesar da diversidade do gênero e das próprias particularidades de cada documento, traços como uma seção de abertura, exórdio, narração, confirmação, peroração e fechamento puderam ser identificados na grande parte dos documentos. Na narração, ou corpo da argumentação, a organização dos documentos mostrou-se centrada nas motivações e, por isso, não foi possível seguir totalmente o plano de crenças de Agrest (2010), havendo apenas ligações entre os dados firmados pela autora e as crenças apresentadas pelos próprios suicidas, em uma representativa ligação do suicídio com o amor não correspondido, não consentido ou não admitido, uma crença que seria não fundada nos limites traçados pela autora.

Tanto na narração quanto na confirmação, o suicida busca afirmar-se, mostra como se sente, faz alguns pedidos e encontra modos de persuadir para que sua palavra seja creditada como verdadeira. Esses pedidos, por sua vez, dependem também de outros dados, como a imagem que esse homem ou mulher tinha ou demonstra ter, uma vez que socialmente não se dá crédito ou atenção às afirmações de indivíduos que são classificados como não tendo reputação (fuga de padrões admitidos e/ou aceitáveis). No inquérito, a carta deixada recebe cuidados e o leitor/interlocutor é chamado a acreditar no que o suicida diz, a dedicar atenção a sua fala. Isso leva, por sua vez, ao mérito que pode ser dado aos argumentos escolhidos para fazer parte da proposição, seus fundamentos que podem e serão contestados, segundo o julgamento das provas, evidências, traços e fatos apresentados. Contudo, o eu suicida parece não querer isso, parece pedir em seu "último contato" que suas razões sejam simplesmente aceitas, sem que haja uma resposta por parte do interlocutor. No texto do suicida discurso se dá por atos assertivos, o que implica uma ação interativa de convencer com o partilhar de uma crença, como demonstraram as análises. O eu suicida representa, pela polifonia do não e do 
mas, sentir-se desafiado pelo que supostamente o interlocutor pensa sobre o que ele diz, uma argumentação pela contrapalavra.

A classificação entre os gêneros retóricos judiciário, epidíctico e deliberativo (apesar da observação de alguns autores de existência de outros gêneros nos mesmos limites traçados por Aristóteles) mostrou-se suficiente no sentido de um enquadramento mais geral ou de predominância nos textos. O caso mais particular do discurso político, o plano retórico ficou ora centrado na acusação, ora no discurso epidíctico em exaltação ou louvor dos atos praticados, com a intenção de provocar um efeito de comunidade em função de um heroísmo. Nesse caso, o auditório era direcionado a unir-se em batalha contra uma força que se colocava sobre valores e direitos a serem defendidos, alterando a ligação do suicídio como falta de discernimento (ruina de si próprio) para uma bandeira de luta engajada, a entrega da vida por amor ou honra a um povo ou nação.

Como questões finais salienta-se que o suicídio preocupa pela quantidade de pessoas que recorrem a esse ato e precisamente por não haver uma idade precisa, nem classe social que se isente. A busca por informações ou esclarecimentos a respeito dessa conduta indica como são variadas as razões ou o quanto são imprecisas as tentativas de identificação desses indivíduos antes que cometam o ato. Deixar ou não deixar algo escrito parece ser também uma incógnita em meio a tantas outras que aparecem junto à prática suicida. O estudo aqui defendido indica atitudes, valores e crenças que são admitidas por alguns desses sujeitos que, ao optarem pela morte voluntária, optam por deixar uma última mensagem escrita, sobretudo com o objetivo de apontar o tipo de ação que desencadeou um processo e interrompeu a normalidade ou trajetória de vida desses sujeitos. Uma desestabilização que aponta para a perda do sentido da vida, medo ou cansaço de viver, fragilidade, perdas profissionais, financeiras e, principalmente, afetivas, ou simplesmente por acreditarem no suicídio como uma única saída ou ponte para um "lugar" melhor.

\section{Referências}

ADAM, J. M. A Linguística Textual: introdução à análise textual dos discursos. São Paulo: Cortez, 2008.

HEIDMANN, U.; MAINGUENEAU, D. Análises textuais e discursivas: metodologias e aplicações. São Paulo: Cortez, 2010.

BONHOMME. L'argumentation publicitaire. Paris: Armand Colin, 2010. 
AGREST, D. C. Por mano propia: estudio sobre las prácticas suicidas. Buenos Aires: Fondo de Cultura Económica, 2010.

ARISTOTELES. Retórica. São Paulo: Edipro, 2011.

BRETON, Philippe. A argumentação na comunicação. Baurú: Edusc, 2003. . A manipulação da palavra. São Paulo: Edições Loyola, 1999.

FGV - Fundação Getúlio Vargas. Disponível em: http://cpdoc.fgv.br/producao/dossies/AEraVargas2/artigos/AlemDaVida/CartaTestamento. Acesso em: 26/05/2012. MAINGUENEAU, D. Cenas da enunciação. Curitiba: Criar Edições, 2006.

. Ethos, cenografia, incorporação. In: AMOSSY, R. Imagens de si no discurso: a construção do ethos. São Paulo: Editora Contexto, 2005, p.69-92.

A propósito do ethos. In: MOTTA, A. R. e SALGADO, L. Ethos discursivo. São Paulo: Editora Contexto, 2008, p.11-29.

OSAKABE, H. Argumentação e discurso político. São Paulo: Kairós, 1979.

PERELMAN, C. TYTECA, L. O. Tratado da argumentação: a nova retórica. São Paulo: Martins Fontes, 1996.

REBOUL, O. Introdução à retórica. São Paulo: Martins Fontes, 2004.

SCHMETZ, R. L'argumentation selon Perelman : pour une raison au coeur de la rhétorique. Bélgica : Namur, 2000. 